\title{
Indicadores de Veranicos e de Distribuição de Chuva no Ceará e os Impactos na Agricultura de Sequeiro
}

\author{
Thaís Braga Carneiro Rocha ${ }^{1,2}$ (D), Francisco das Chagas Vasconcelos Júnior ${ }^{1,2}$ (D), \\ Cleiton da Silva Silveira ${ }^{3}$ (D), Eduardo Sávio Passos Rodrigues Martins ${ }^{1}$ (D), \\ Suellen Teixeira Nobre Gonçalves ${ }^{1,2}$ (D), Emerson Mariano da Silva² (D), \\ José Maria Brabo Alves $^{2}$ (D), Meiry Sayuri Sakamoto ${ }^{1,2}$ \\ ${ }^{1}$ Fundação Cearense de Meteorologia e Recursos Hídricos, Fortaleza, CE, Brasil. \\ ${ }^{2}$ Mestrado Profissional em Climatologia e Aplicações nos Países da CPLP e África, Universidade \\ Estadual do Ceará, Fortaleza, CE, Brasil. \\ ${ }^{3}$ Universidade Federal do Ceará, Fortaleza, CE, Brasil
}

Recebido em: 22 de Maio de 2019 - Aceito em: 2 de Março de 2021

\begin{abstract}
Resumo
O Nordeste do Brasil apresenta acentuada variabilidade interanual da precipitação com alguns anos secos e outros chuvosos. Nessa região, ocorrem os veranicos, que são dias consecutivos com ausência de precipitação durante o período da estação chuvosa, que ocasionam perdas nas safras agrícolas. O presente artigo tem como objetivo utilizar um indicador de veranicos já estabelecido por outros autores e identificar sua relação com o Índice de Distribuição de Chuva e regionalizar de acordo com as macrorregiões do estado, bem como, compreender as possíveis consequências, de forma qualitativa e quantitativa, sobre as perdas de safra no Ceará. A área de estudo compreendeu o estado do Ceará e as análises foram realizadas para o período de 1980 a 2018.A partir dos dados de rendimento do IBGE, foram calculadas as perdas das culturas do milho e feijão, e através dos resultados pode-se inferir que: as correlações realizadas com os dados de perdas de safra, veranicos e o IDC evidenciaram que para a maior parte do estado existe correlação direta, ou seja, quanto maior a frequência de eventos de veranicos maior a perda de safra. Além disso, verificou-se que, quando há uma melhor distribuição da precipitação ao longo das regiões do estado ocorre menor perda de safra.
\end{abstract}

Palavras-chave: indicador, precipitação, safra, veranicos.

\section{Indicators of Dry Spells and Distribution of Rain in Ceará and the Impacts on Rainfed Agriculture}

\begin{abstract}
Northeastern Brazil has marked interannual rainfall variability with some dry and other rainy years. In this region, there are dry spells, which are consecutive days with no rainfall during the rainy season, causing losses in agricultural crops. This article aims to use an indicator of Indian summers already established by other authors 2020 and identify its relationship with the Rain Distribution Index and regionalize according to the state's macro-regions, as well as understand the possible consequences, in a qualitative and quantitative way. on crop losses in Ceará. The study area comprised the state of Ceará and the analyzes were carried out for the period from 1980 to 2018. From the IBGE yield data, the losses of corn and beans crops were calculated, and through the results it can be inferred that: the correlations made with data on crop losses, summer and the IDC showed that for the largest part of the state there is a direct correlation, that is, the higher the frequency of summer events, the greater the crop loss. In addition, it was found that when there is a better distribution of precipitation over the regions of the state, less crop loss occurs.
\end{abstract}

Keywords: indicator, precipitation, crop, dry spells.

Autor de correspondência: Thaís Braga Carneiro Rocha, thaisbraga10@gmail.com. 


\section{Introdução}

O semiárido do Nordeste do Brasil possui uma área de $1.128 .267 \mathrm{~km}^{2}$ e um total de 1.262 municípios. Essa região apresenta variabilidades geográficas e climáticas espaciais que podem resultar em escassez hídrica e vulnerabilidade dos recursos naturais (SUDENE, 2017; Fernandes, 2014).

Além disso, o Nordeste apresenta acentuada variabilidade interanual da precipitação com alguns anos secos e outros chuvosos (Calvacanti et al., 2009). O Ceará está localizado na porção Nordeste do Brasil (NEB), apresenta clima predominante semiárido e seu regime de precipitação é bastante irregular. Devido à alta variabilidade pluviométrica, a região passa a ser acometida por fenômenos como inundações e secas (Chaves e Cavalcanti, 2001).

A precipitação neste estado concentra-se nos primeiros meses do ano, dividindo-se em pré-estação que ocorre entre dezembro e a primeira quinzena de fevereiro e a estação chuvosa que acontece no período de fevereiro a maio (Souza et al, 1996; Meneses, 2007).

Sazonalmente, a variabilidade é bem definida, por apresentar um período chuvoso e outro seco (Silva et al., 2012). Os valores da precipitação média podem ficar em torno de $500 \mathrm{~mm} /$ ano em algumas regiões do Sertão do Inhamuns e podem ultrapassar $1.400 \mathrm{~mm} / \mathrm{ano}$ na no litoral de Fortaleza. Na Serra da Ibiapaba o acumulado de chuvas pode ficar acima de $1.800 \mathrm{~mm} /$ ano e na Chapada do Araripe em torno de $1.000 \mathrm{~mm} / \mathrm{ano}$ (Coutinho et al. 2010).

A baixa disponibilidade hídrica do estado bem como os veranicos (que são dias consecutivos com ausência de precipitação durante a estação chuvosa) é ocasionada por algumas condições, das quais pode-se destacar: (a) precipitações baixas (inferiores a $900 \mathrm{~mm}$ ); (b) evaporação superior a $2.000 \mathrm{~mm}$; (c) hidrogeologia desfavorável (cerca de $80 \%$ do território está sobre rocha cristalina, com uma camada de solo raso e escassos recursos hídricos subterrâneos); (d) um regime de precipitação irregular (secas recorrentes, por vários anos consecutivos) (Nascimento et al., 2018).

Os veranicos também afetam a produtividade das culturas, especialmente quando ocorrem na fase na qual a planta é mais sensível à deficiência hídrica (Carvalho et al., 2000). Na agricultura familiar no Ceará destacam-se os cultivos de milho e feijão, que segundo os dados do IBGE (2017), correspondem a $91,0 \%$ das áreas cultivadas no estado.

Neste contexto, os objetivos deste estudo foram: avaliar um indicador de veranicos e identificar sua relação com o Índice de Distribuição de Chuva e regionalizar de acordo com as macrorregiões do estado, bem como, compreender as possíveis consequências, de forma qualitativa e quantitativa, sobre as perdas de safra no Ceará.

\section{Materiais e Métodos}

A região de estudo compreende o estado do Ceará. Foram obtidos os dados de precipitações diárias dos postos pluviométricos e rendimento das produções de sequeiro do milho e feijão. A partir disso, foi possível classificar os tamanhos dos eventos de veranicos e utilizar um indicador para simplificar a avaliação dos mesmos. Já com as variáveis de rendimento, foram calculadas as porcentagens das perdas de produtividade. A descrição das etapas do cálculo do indicador, as perdas de safra e os resultados obtidos serão apresentados nas próximas subseções.

\section{1 Área de estudo}

O estado do Ceará está localizado no Nordeste do Brasil e apresenta uma área de, aproximadamente, $148.826 \mathrm{~km} 2$, que corresponde a 9,6\% da área do NEB. Segundo o IBGE (2010), o estado conta com 8.452.381 habitantes e divide-se em 184 municípios.

Com objetivo de melhor representar as regiões do estado, algumas instituições como a FUNCEME, utilizam a regionalização definida por Xavier (2001), na qual o estado é dividido em oito macrorregiões pluviometricamente homogêneas. Cada macrorregião reúne municípios que apresentam regime de chuvas com as mesmas características, como demonstra a Fig. 1 (Estado do Ceará, 2010; IBGE, 2010; Xavier, 2001).

\subsection{Dados de precipitação}

O período adotado para o presente estudo, foram os meses de fevereiro a maio dos anos de 1980 a 2018, por melhor representarem a estação chuvosa. Os dados utilizados foram provenientes do banco de dados da FUNCEME, sendo posteriormente, modificados para dados diários por município através do método de média por polígonos de Thiessen. Utilizou-se apenas os períodos que apresentavam mais de $70 \%$ de dados válidos de precipitação diária.

\subsection{Dados de produção agrícola}

Para o cálculo da perda de safra foram utilizados os anos de 1980 a 2018 e os dados de rendimento médio da produção $(\mathrm{kg} / \mathrm{ha})$ das culturas de milho (Zea mays L.) e do feijão (Vigna Unguiculata L. Walp.) foram provenientes da Tabela 1612 de Produção Agrícola Municipal, do Sistema IBGE (Instituto Brasileiro de Geografia e Estatística) de Recuperação Automática (SIDRA) que reúne dados por ano e por município do estado do Ceará.

\subsection{Cálculos do indicador de veranicos}

Os veranicos foram classificados como três ou mais dias consecutivos com precipitação diária igual ou inferior a $2 \mathrm{~mm}$ (conforme proposto por Menezes et al., 2008). A partir dessa definição, foi determinado os tamanhos de veranicos, em função da quantidade de dias consecutivos, 

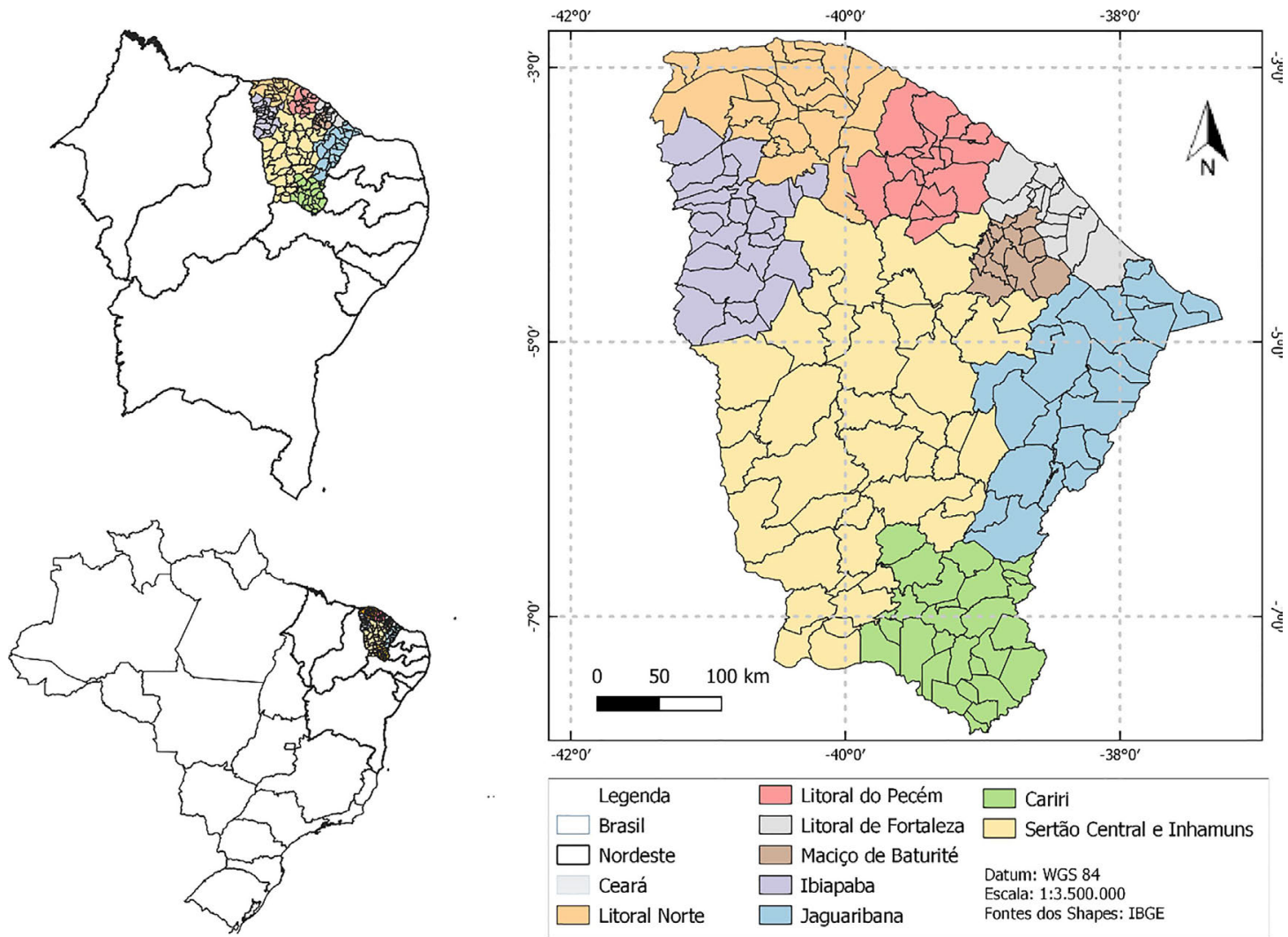

Figura 1 - Mapa de localização do estado do Ceará com a delimitação territorial dos seus municípios e as oito macrorregiões pluviometricamente homogêneas.

escolhendo veranicos de 3 a 5,6 a 10,11 a 15,16 a 20 e acima de 20 dias. Com esses tamanhos definidos, os eventos de veranicos por município foram divididos em graus de veranicos.

Dessa forma, foram atribuídos pesos para cada grau e a partir deles foi utilizado o método matemático de progressão geométrica. Nesse método, a partir do segundo elemento da fórmula, o peso é igual ao produto do peso anterior por uma constante (valor 2). O peso mais elevado foi para o grau 5, por representar veranicos com maiores durações, conforme Tabela 1.

Dessa forma, Rocha et al. (2020) desenvolveu o Indicador de Veranicos com o objetivo de simplificar a análise dos veranicos, no qual cada peso é multiplicado por seu respectivo grau, com fórmula demonstrada na Eq. (1). O índice foi calculado do período de fevereiro a maio

$$
i v=\frac{P 1 * G 1+P 2 * G 2+P 3 * G 3+P 4 * G 4+P 5 * G 5}{P T}
$$

onde $i v$ indicador de veranico; $P$ : peso de cada grau, por exemplo, 1 para grau 1; $G$ : o valor correspondente de cada grau, por exemplo, o valor do grau 1 para o peso $1 ; P T$ : somatório de todos os pesos.
Com os resultados são gerados mapas utilizando escala com valores de 0 a 2 , dessa forma quanto mais próximo do 2 , mas intenso é o indicador.

\subsection{Cálculos do IDC (Índice de Distribuição de Chuva)}

O Índice de Distribuição de Chuva (IDC) foi inicialmente proposto pela FUNCEME e adaptado para o presente estudo. Esse índice foi originado para o desenvolvimento de culturas agrícolas e relaciona variações volumétricas, temporal e espacial da chuva, sendo um indicador um contraponto do indicador de veranicos. Para o cálculo desse índice foi utilizado o mesmo parâmetro de precipitação do veranico, isto é, chuva acima de $2 \mathrm{~mm}$. Para a obtenção do IDC, é necessário calcular, em primeiro lugar, o índice de seca, conforme demonstrado na

Tabela 1 - Graus de veranico e seus pesos.

\begin{tabular}{lcc}
\hline Graus de veranicos & Tamanho dos eventos (dias) & Peso dos Graus \\
\hline Grau 1 & 3 a 5 & $\mathrm{P}_{1}=1$ \\
Grau 2 & 6 a 10 & $\mathrm{P}_{2}=2$ \\
Grau 3 & 11 a 15 & $\mathrm{P}_{3}=4$ \\
Grau 4 & 16 a 20 & $\mathrm{P}_{4}=8$ \\
Grau 5 & Acima de 20 & $\mathrm{P}_{4}=16$ \\
\hline
\end{tabular}

Fonte: Rocha et al (2020). 
Eq. (2):

$$
\text { indice de seca }=\frac{\text { Nd chuva } * \text { Nd } 15 * \text { Prec }}{N d(\text { Nd-Maior sem chuva })}
$$

onde Nd chuva: Número de dias com chuva; $N d$ 15: Número de dias do maior período de chuva, no qual não ocorreu um veranico igual ou superior a 15 dias; Prec: Precipitação observada no município; $N d$ : Número de dias do período escolhido; Maior sem chuva: Duração em dias do maior período sem chuva.

A partir dos valores do índice de seca, foi possível calcular o IDC, conforme a Eq. (3):

$$
I D C=\frac{1000 * \text { índice de seca }}{\text { Precpitação média do Ceará no período }}
$$

Para auxiliar na avaliação do índice, foram definidas as categorias do IDC para distinguir os municípios e classificar o período chuvoso (fevereiro a maio). Dessa forma, foi categorizado o índice como demonstra a Tabela 2.

Através dessa tabela verifica-se que um município em categoria crítica, é o que apresenta um pior estado de distribuição de chuvas, ocorrendo o oposto em um município na categoria excelente.

\subsection{Cálculo das perdas de rendimento de safra}

As culturas escolhidas para o presente estudo foram: milho e feijão, e a variável a ser estudada: rendimento médio da produção $(\mathrm{kg} / \mathrm{ha})$. As porcentagens das perdas do rendimento foram obtidas utilizando a metodologia proposta por Rocha et al. (2020) através da Eq. (4):

$$
P R=\frac{R a-R \max }{R \max } * 100
$$

onde $P R$ : Valor anual em porcentagem que representa o valor da perda, em termos de rendimento, para cada município para o tipo de cultura milho/feijão; $R a$ : valor correspondente ao rendimento $(\mathrm{kg} / \mathrm{ha})$ de cada ano do milho/ feijão; Rmax: valor correspondente ao máximo do rendimento de todos os anos do milho/feijão.

\subsection{Cálculo das correlações}

A correlação tem como objetivo verificar se há associação entre as variáveis em estudo. Dessa forma, com a finalidade de buscar relação entre resultados obtidos foram

Tabela 2 - IDC.

\begin{tabular}{lc}
\hline Categorias IDC & Níveis \\
\hline Excelente & Acima de 1000 \\
Muito Bom & 301 a 1000 \\
Bom & 201 a 300 \\
Regular & 101 a 200 \\
Crítica & 0 a 100 \\
\hline
\end{tabular}

realizadas correlações entre as Perdas de Safra (milho e feijão) com os Número de Veranicos e o IDC.

Para o presente estudo foi utilizada a correlação de Pearson (r), também conhecida como linear ou $r$ de Pearson. Essa correlação tem valores entre $-1 \mathrm{e}+1$, quando os valores estão mais próximos de +1 , mais forte é a relação linear positiva entre as variáveis, quando se aproxima de -1 é chamado de correlação linear inversa e quando se aproxima do valor zero, não existe correlação entre as variáveis em estudo. Dessa forma, quanto mais se aproxima de $-1 \mathrm{e}+1$ a correlação é mais intensa, seja diretamente ou inversamente proporcional (Paranhos et al., 2014).

Desse modo, os anos foram categorizados com base nos limiares dos tercis 33 e $66 \%$ relacionado ao acumulado anual de precipitação no Ceará para o período climatológico de 1981-2010, ou seja, chuvoso (acima do limiar $66 \%$ ), normal (entre o limiar de 33 e 66\%), e seco (abaixo do limiar de $33 \%$ ). Nesse sentido, foram selecionados os anos de: 1993 (ano seco); 2018 (ano normal); 1989 (ano chuvoso), por representarem anos de contrastes climáticos para associar perdas de safra com o indicador de veranico e o IDC. Foram comparados os seus respectivos mapas com os acumulados de precipitação $(\mathrm{mm})$ e os desvios (mm) para os meses da estação chuvosa (Fevereiro a Maio).

\section{Resultados e Discussões}

A partir dos resultados obtidos, foram realizados os cálculos das médias para cada indicador: indicador de veranicos $(0,74)$ e IDC $(370,72)$. As perdas de safra das duas culturas tiveram médias semelhantes para o período analisado (1980 a 2018): feijão $(52,34 \%)$ e milho $(58,65 \%)$. Além disso, consideraram-se os valores do limite inferior e do limite superior da faixa normal anual do estado, nos quais o limite inferior corresponde a $674,56 \mathrm{~mm}$ e o limite superior corresponde a $926,69 \mathrm{~mm}$.

\subsection{Correlações temporais}

A Fig. 2 apresenta as informações da correlação realizada entre as Perdas de Safra do Milho e Feijão com os resultados obtidos para o indicador de veranicos. A partir das informações contidas nessa figura, é possível perceber que, para a cultura do milho a maior parte do estado teve correlação positiva, ou seja, quanto maior o indicador de veranicos maior a perda de safra dessa cultura. Na região Jaguaribana ocorreram correlações próximas a zero, com destaque para o município de Limoeiro do Norte, no qual a correlação linear foi inversa com um valor de $-0,3$. Para a cultura do feijão a correlação linear positiva mais alta foi na região do Sertão Central e Inhamuns e a região Jaguaribana apresentou municípios com correlações negativas.

A correlação para a cultura do feijão não foi conforme esperado para todo o estado, principalmente, para a região Jaguaribana. Essa região deve ser avaliada de acor- 

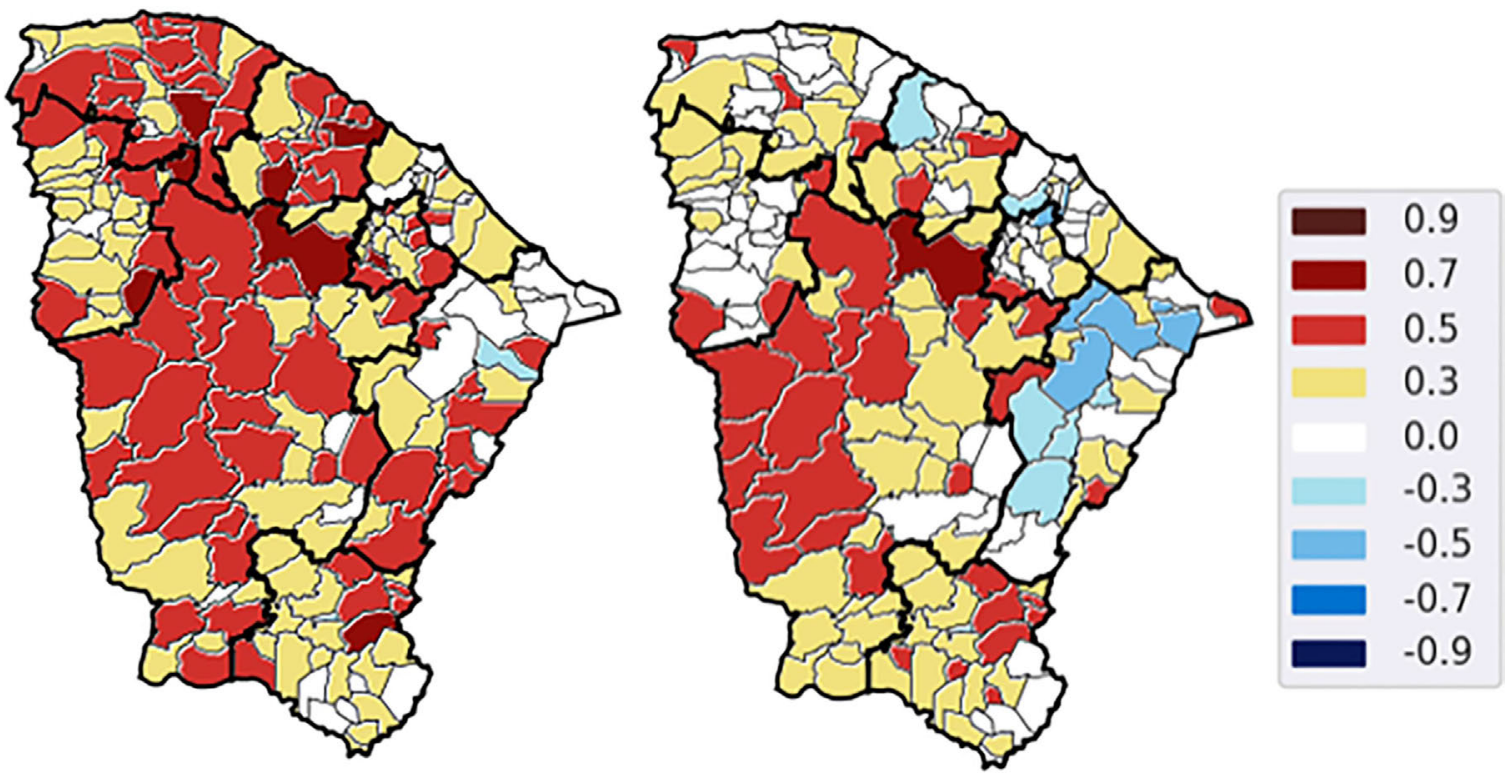

Figura 2 - Correlação entre Perda de Safra Milho (esquerda) e Feijão (direita) e Número de Veranicos nos municípios do Ceará.

do com outros fatores que podem ter favorecido um melhor rendimento para a cultura do feijão, ainda que houvesse muitos eventos de veranicos. Nesta região, localizase o Perímetro Irrigado Jaguaribe Apodi, no município de Limoeiro do Norte, no qual o suprimento hídrico é assegurado pelo Rio Jaguaribe. Esse perímetro, possivelmente, seria a justificativa para a correlação inversa, já que algumas culturas desta região utilizam a técnica da irrigação, apesar de que os dados do IBGE se referem às culturas de sequeiro.

Dessa forma, a partir das informações da Fig. 2, a cultura do milho apresentou maiores correlações com o número de veranicos, ainda que, principalmente a região Jaguaribana tenha apresentado correlação inversa. Demonstrando que, a porção norte dessa região possui menor vulnerabilidade para a ocorrência de veranicos.

A Fig. 3 representa a correlação entre as de Perdas de Safra do Milho e do Feijão com o IDC, é possível perceber que, para as duas culturas a maior parte do estado teve correlação linear inversa, ou seja, quanto maior o IDC menor a perda de safra para cada cultura. Com destaque para região Jaguaribana, que apresentou o município de Limoeiro do Norte com correlação linear positiva, porém essa não foi tão intensa com um valor de 0,3. Alguns


Figura 3 - Correlação entre a Perda de Safra Milho (esquerda) e Feijão (direita) e o IDC nos municípios do Ceará. 
municípios tiveram correlações iguais a zero, o que indica uma falta de relação entre as variáveis.

Essa correlação também indica que, o resultado obtido não foi o esperado ao longo de todo estado e pode-se notar, principalmente, na região Jaguaribana, onde foram obtidas correlações inversas. Nesse sentido, se faz necessário, avaliar outros fatores que poderiam contribuir para reduzir a perda de safra de cada região do estado.

\subsection{Ano seco}

O ano de 1993 representou uma das maiores secas do estado, sendo portanto, considerado um ano seco. Segundo os dados do Calendário de Chuvas da FUNCEME, neste ano o desvio foi abaixo da normal climatológica, com um valor de $-52,9 \%$ e a sua estação chuvosa (fevereiro a maio) também foi abaixo da normal com valor de $-52,0 \%$ (Fig. $4 \mathrm{~b}$ ). Além disso, ao considerar os valores do limite inferior $(674,56 \mathrm{~mm})$ e do limite superior $(926,69 \mathrm{~mm})$ da faixa normal anual do estado, o acumulado anual deste ano esteve bem abaixo do limite inferior com o valor observado de $376,9 \mathrm{~mm}$. O indicador de veranicos médio sobre o estado ficou em 1,06, o qual representa uma variação de 0,30 em relação à média climatológica na escala do índice $(0,76)$, o que significa uma variação de $39 \%$.

No que se refere às perdas de safra para esse ano (Figs. 4d-e) para a cultura do milho, foram observadas perdas significativas na maior parte do estado, com valores acima de 90,0\%, principalmente, no Sertão Central e Inhamuns. Esta perda pode ser explicada pela irregularidade da chuva. Para a cultura do feijão (Figs. 4e), a região Jaguaribana apresentou perdas de safra mínimas. A Fig. 4b, apre-

a)



b)

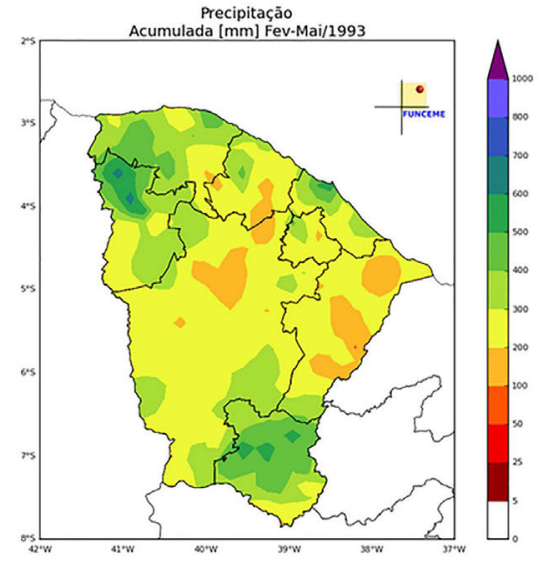

Precipitação

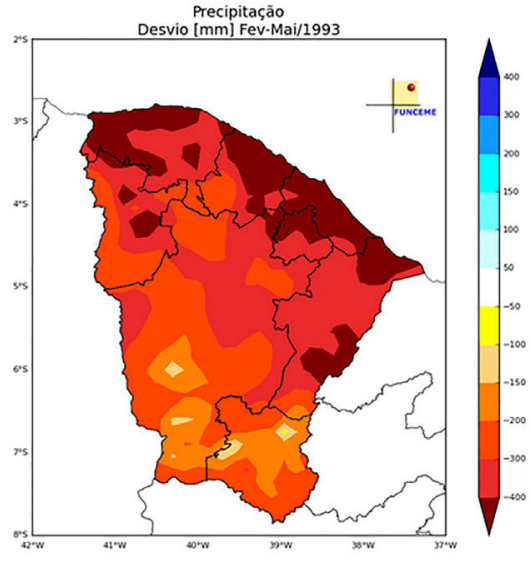

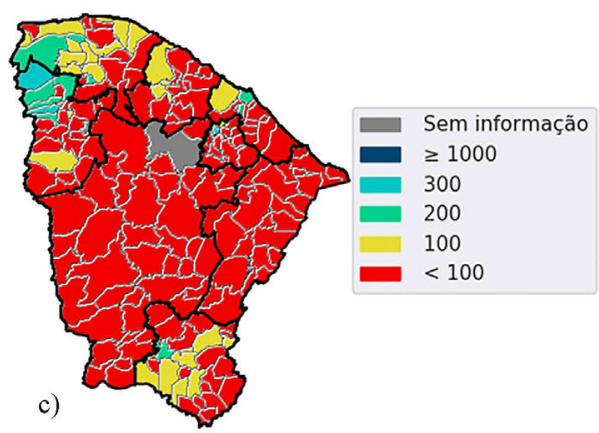
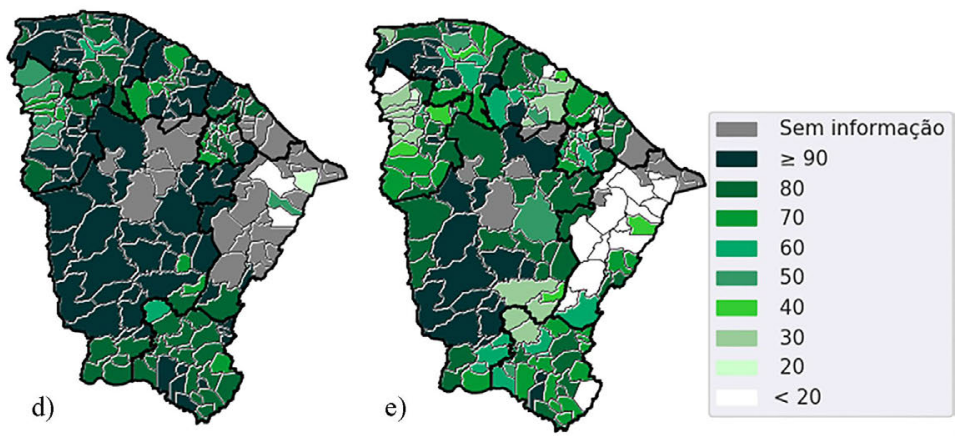

Figura 4 - Fevereiro a Maio de 1993: a) Indicador de Veranicos; b) Precipitação Acumulada (mm) e Desvio (mm); c) IDC; Perdas de safra - rendimento (\%) - d)milho, e) feijão. Fonte: a) Elaborado pela autora; b): FUNCEME. 
senta a precipitação acumulada e o desvio, este último foi mais intenso na porção noroeste e nordeste do estado do Ceará. O indicador de veranicos (Fig. 4a) mostrou menores ocorrências na região do Litoral Norte (mesmo com desvios negativos de chuva extremos para essas regiões).

A partir das informações contidas no mapa do IDC (Fig. 4c) e do indicador de veranicos (Fig. 4a), é possível verificar que a região Litoral Norte apresentou municípios com menores ocorrências de veranicos. Essa característica é reiterada no mapa do IDC, onde o índice apresenta um mínimo. Além disso, verifica-se que nas regiões que ocorreram as menores precipitações acumuladas, como a Sertão Central e Inhamuns e Jaguaribana, foram as regiões em que o IDC apresentou os menores valores do índice
(Fig. 4c). Esses dois fatores, explicam os maiores e mais frequentes veranicos e as perdas de safra associadas para este ano.

\subsection{Ano normal}

O ano de 2018, apresentou volume de chuvas semelhante a normal climatológica, com um valor de $+0,2 \% \mathrm{e}$ para o período da estação chuvosa o desvio foi de $0,0 \%$ (Fig. 5b).

$\mathrm{O}$ indicador de veranicos médio sobre o estado ficou em 0,62 , o que representa uma variação de $-0,14$ em relação à média climatológica na escala do índice $(0,76)$, o que significa uma variação de $18,42 \%$.

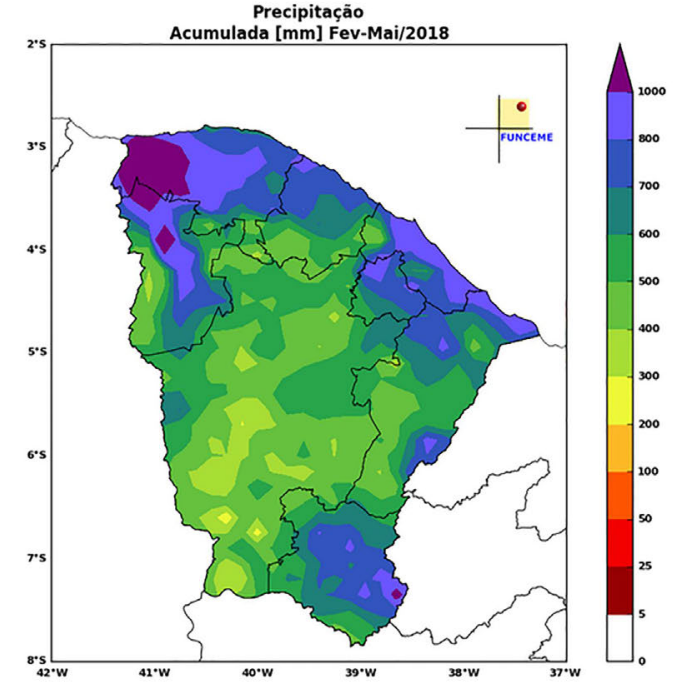

a)

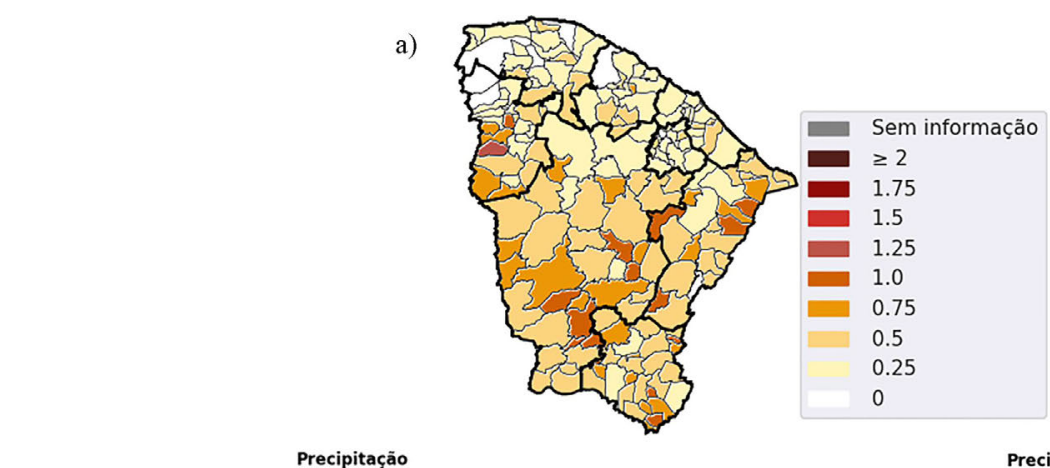

b)

b)

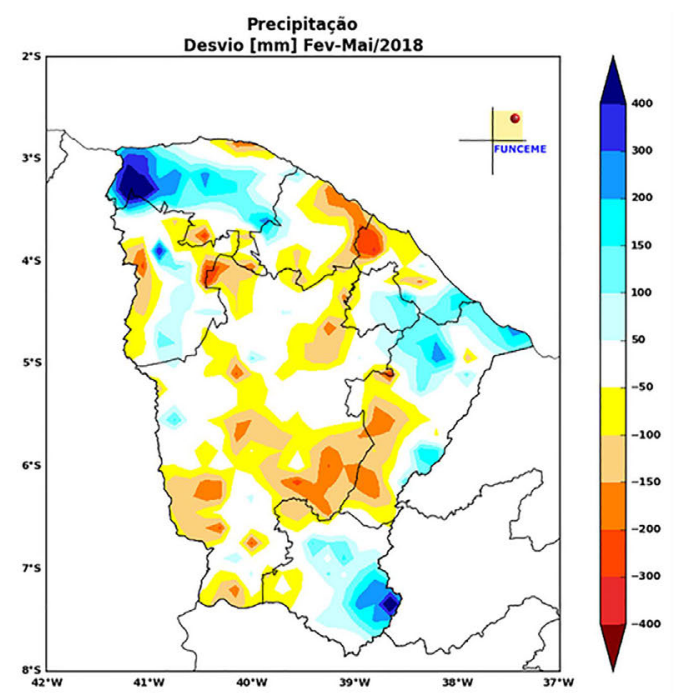

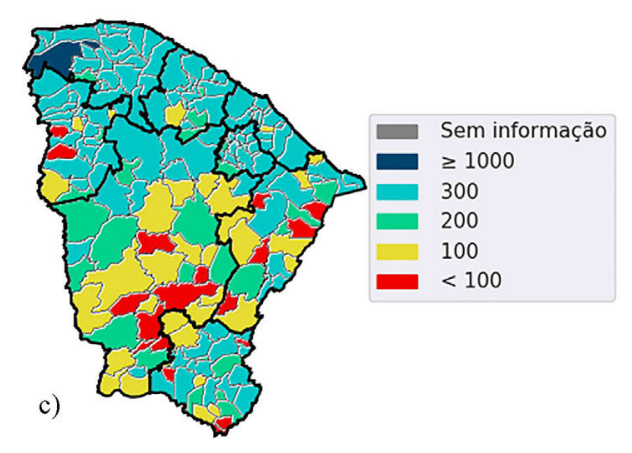


Figura 5 - Fevereiro a Maio de 2018: a) Indicador de Veranicos; b) Precipitação Acumulada (mm) e Desvio (mm); c) IDC; Perdas de safra - rendimento (\%) - d)milho, e) feijão. Fonte: a) Elaborado pela autora; b): FUNCEME. 
No que se refere às perdas de safra (Figs. 5d-e), houve regiões com baixas perdas de safra e outras com altas perdas de safra. As altas perdas de safra ocorreram, principalmente, nas regiões Sertão Central e Inhamuns, Ibiapaba e Jaguaribana para as duas culturas. As regiões Litoral do Pécem, Cariri e porção oeste do Litoral Norte (Fig. 5b), foram onde ocorreram maiores acumulados de precipitação e maiores desvios em relação à média (Fig. 5b). Para essas regiões, houve menores perdas de safra provavelmente pelas boas precipitac?ões que ocorreram nesse ano.

Ao analisar os mapas do IDC (Fig. 5c) e do indicador de veranicos, é possível perceber que os municípios em que houve maiores eventos de veranicos como os municípios das porções leste da região da Ibiapaba, nordeste e sul da região Sertão Central e Inhamuns, sul e nor- deste do Cariri, nordeste, noroeste e sul da Jaguaribana foram os que apresentaram menores valores para o IDC, dessa forma, muitos municípios atingiram situação crítica. As regiões que apresentaram os menores valores do IDC foram também aquelas que apresentaram menores precipitações acumuladas (Fig. 5b).

\subsection{Ano chuvoso}

O ano de 1989 representou um dos maiores volumes acumulados de chuva das últimas décadas no estado. Segundo os dados do Calendário de Chuvas da FUNCEME, neste ano o desvio foi acima da média climatológica, com um valor de $+44,1 \%$ e a estação chuvosa também com desvio de $+35,4 \%$ (Fig. 6b). Além disso, ao considerar os valores do limite inferior e do limite superior b)



a)

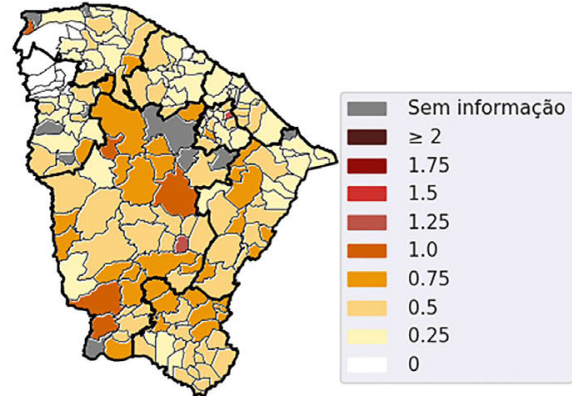


da faixa normal anual do estado, esse ano esteve acima do limite superior com o valor observado de $1153,9 \mathrm{~mm}$.

$\mathrm{O}$ indicador apresentou muitos eventos de veranicos para esse ano, que foram mais intensos na região do Sertão Central e Inhamuns (Fig. 6a). Além disso, mostrou que as regiões Sertão Central e Inhamuns, Cariri, Jaguaribana, Maciço de Baturité, nas porções centro e sul da Ibiapaba e Jaguaribana, sul do Litoral Norte e sul do Litoral de Pecém, foram as que ocorreram maiores eventos de veranicos, entretanto, os desvios de precipitação foram para todo estado bem acima da normalidade (Fig. 6b), porém ainda ocorreram perdas significativas para as duas culturas analisadas (Figs. 6 d-e). O indicador de veranicos médio sobre o estado ficou em 0,59 , o qual representa uma variação de $-0,15$ em relação à média climatológica na escala do índice $(0,74)$, o que significa uma variação de $-20,27 \%$

As perdas de safra para esse ano (Figs. 6 d-e), foram significativas em quase todo estado para as duas culturas, com valores em média de $70 \%$, com maiores perdas principalmente, nas regiões Sertão Central e Inhamuns, Cariri e Jaguaribana, provocadas possivelmente pelo excesso de chuvas observado nesse ano. A região do Litoral Norte foi a que apresentou menores perdas de safra para a cultura do milho, enquanto que, para a cultura do feijão foi a região da Ibiapaba (Figs. 6 d-e). Os desvios e precipitação acumulada nessas regiões durante a estação chuvosa foram intensas (Fig. 6b).

O IDC (Figura 6c) quando comparado com o indicador de veranicos, mostrou que nos municípios em que houve menores ocorrências de veranicos (no nordeste do Litoral Norte e sul da Ibiapaba) foram aqueles em que o índice foi mais intenso, relacionando assim, a distribuição de chuvas com os veranicos. Quando o IDC (Fig. 6c) é comparado com a precipitação acumulada (Fig. 6b), notase que, nas porções que ocorreram as menores precipitações acumuladas, como a porção sul e norte do Sertão Central e Inhamuns, oeste do Litoral de Pecém, leste do Litoral Norte foram as que apresentaram valor de IDC mais baixo.

A Tabela 3 o valores médidos dos indicadores e das perdas de safra por região do estado utilizados nesse estudo.

\section{Considerações Finais}

Neste trabalho foram analisadas as ocorrências de veranicos com os dados de perdas de safras para as culturas de milho e feijão, IDC, a precipitação acumulada e o desvio para todos os municípios do estado do Ceará, durante o período de 1980 a 2018. Foram selecionados três anos para análise em função dos acumulados de precipitação e de acordo com os limiares dos tercis foram categorizados em anos secos, normais e chuvosos, a fim de investigar a sensibilidade e relação entre a informação

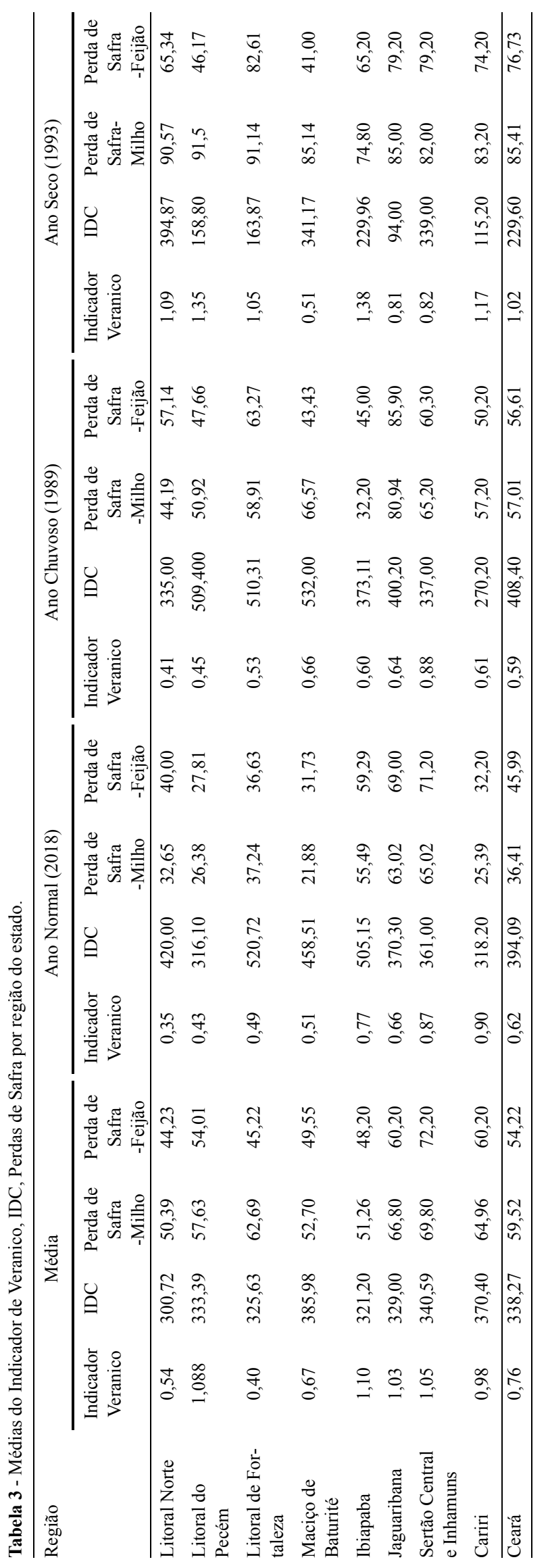


regionalizada dos veranicos durante o período chuvoso e às perdas de safra no estado do Ceará em cada ano.

As correlações realizadas com os dados de perdas de safra, veranicos e o IDC evidenciaram que para a maior parte do estado existe correlação direta, ou seja, quanto maior a frequência de eventos de veranicos maior a perda de safra. Além disso, verificou-se que, quando há uma melhor distribuição da precipitação ao longo das regiões do estado ocorre menor perda de safra. Porém, isso não ocorreu para todo estado, por exemplo, na região Jaguaribana as correlações obtidas não seguiram esse padrão. Isso evidencia a necessidade de avaliar outros fatores de cada região, como por exemplo, a questão de solo e preparação do plantio.

Em anos chuvosos foram verificadas reduzidas ocorrências de veranicos e melhor distribuição das chuvas ao longo do estado. Entretanto, ocorreram perdas de safra significativas para as duas culturas, isso ocorre porque o excesso de chuva ocasiona um solo saturado do ponto de vista hídrico o que prejudica o plantio por ser desfavorável em algumas fases do cultivo da cultura.

Nos anos secos foram verificadas maiores ocorrências de veranicos e má distribuição das chuvas ao longo do estado. Dessa forma, as perdas de safra foram intensas, ocasionadas pela escassez hídrica que nas primeiras fases fenológicas provocam maiores dificuldades para absorção de nutrientes.

Nos anos normais, no qual existe uma maior regularidade na precipitação, as perdas de safra foram menores nas culturas de sequeiro analisadas. Dessa forma, quando ocorre anos extremos (anos secos ou muito chuvosos) as culturas estão mais suscetíveis à ocorrência de perdas de safra.

Existe uma relação entre a ocorrência dos veranicos, distribuição e acumulados de chuvas durante estação chuvosa e as perdas de safra no estado do Ceará. Porém, essa relação não ocorre em todo estado, o que evidencia a importância de regionalizar para avaliar as perdas de safra.

As perdas de safras podem ser minimizadas com a utilização de tecnologias relacionadas a estimativa da variação temporal dos veranicos ao longo do período chuvoso com base em previsão sazonal. Além disso, deve ser incentivado a elaboração de um calendário agrícola apropriado (definindo qual o melhor período para realizar o plantio e a colheita das culturas). Essas ações devem ser realizadas de forma a prevenir intensas perdas de safra, principalmente, em anos em que o prognóstico climático indicar a ocorrência de extremos.

\section{Agradecimentos}

A Universidade Estadual do Ceará pela criação do curso de Mestrado Profissional em Climatologia e países da CPLP. A FUNCEME e a Empresa de Assistência Técnica e Extensão Rural do Ceará (EMATERCE) por todo apoio para o desenvolvimento dessa pesquisa.

\section{Referências}

CARVALHO, D.F.; FARIA, R.A.; SOUSA, S.A.V.; BORGES, H.Q. Espacialização do período de veranico para diferentes níveis de perda de produção na cultura do milho, na bacia do Rio Verde Grande, MG. Revista Brasileira de Engenharia Agrícola e Ambiental, v. 4, n. 2, p. 172-176, 2000.

CAVALCANTI, I.F.A.; FERREIRA, J.F.; SILVA, M.G.A.J.; DIAS, M.A.F.S. Tempo e Clima no Brasil. São Paulo: Oficina de Textos, 2009.

CEARÁ. Ceará em Números. 2010. Disponível em https:// www.ceara.gov.br/2010/03/13/ceara-em-numeros/. Acesso em 05 fev. 2021.

CHAVES, R.R.; CAVALCANTI, I.F.A. Atmospheric circulation features associated with rainfall variability over southern Northeast Brazil.Mon. Wea. Rev., v. 129, n. 10, p. 26142626, 2001.

COUTINHO, M.D.L.; BRITO, J.I.B. Análise de componentes principais com dados pluviométricos no estado do Ceará. In: A Amazônia e o Clima Global. Belém: Congresso Brasileiro de Meteorologia, 2010.

FERNANDES, F.B.P. Disponibilidade Hídrica para a Cultura do Feijão-de-Corda em Função do Manejo de Solo no Semiárido Cearense. Tese de Doutorado em Engenharia Agrícola, Centro de Ciências Agrárias, Universidade Federal do Ceará, Fortaleza, 111 p., 2014.

IBGE - Instituto Brasileiro de Geografia e Estatística. Censo Agro 2017. 2017. Disponível em https://censos.ibge.gov. br/agro/2017/templates/censo_agro/resultadosagro/produtores.html?localidade=23. Acesso em 12 fev. 2021.

IBGE - Instituto Brasileiro de Geografia e Estatística. Resultado dos Dados Preliminares do Censo - 2010, 2010. Disponível em www.ibge.gov.br/cidade@, acesso em 22 maio 2019.

MENESES, G.M.L. Análise E Estimativa Da Produtividade Da Cultura Da Mamona Para Produção De Biodiesel Em Função Do Período Chuvoso No Estado Do Ceará, 2007. Disponível em http://www.dominiopublico.gov.br/ pesquisa/DetalheObraForm.do?select_action=\&co_obra $=185909$. Acesso em 2 fev. 2021.

MENEZES, H.E.A.; BRITO J.I.B.; SANTOS, C.A.C.; SILVA, L. A relação entre a temperatura da superfície dos oceanos tropicais e a duração dos veranicos no Estado da Paraíba. Revista Brasileira de Meteorologia, v. 23, n. 2, p. 152$161,2008$.

NASCIMENTO, N.O.; SILVA, S.M.O.; MELO, M.C.; FORMIGA-JOHNSON. R.M.; SOUZA FILHO, F.A. Segurança Hídrica Em Metrópoles Brasileiras. Águas do Brasil: O Futuro com Água Depende de Nós, São Paulo, p. 36-41, ago. 2018. Disponível em http://aguasdobrasil.org/revistaaguas-do-brasil-22/. Acesso em 5 fev. 2021.

PARANHOS, R. et al. Desvendando os Mistérios do Coeficiente de Correlação de Pearson: o Retorno. 2014. Disponível em: https://www.revistas.usp.br/leviathan/article/ view/132346. Acesso em 22 fev. 2021. 
ROCHA, T.B.C; VASCONCELOS JUNIOR, F.C.; SILVEIRA, C.S.; MARTINS, E.S.P.R.; SILVA, R.F.V. Veranicos no Ceará e Aplicações para Agricultura de Sequeiro. Revista Brasileira de Meteorologia, v. 35 n. 3, 435-447, 2020

SILVA, D.F. da; SOUSA, A.B. de; MAIA, L.M; RUFINO, L.L. Efeitos da Associação de Eventos de ENOS e ODP Sobre o Estadodo Ceará. 2012. Disponível em https://periodicos.ufpe.br/revistas/revistageografia/article/view/ 228968. Acesso em 23 fev. 2021.

SILVA, F.A.S.; RAO, T.V.R. Regimes pluviais, estação chuvosa e probabilidade de ocorrência de veranicos no estado do Ceará. Revista Brasileira de Engenharia Agrícola e Ambiental, v. 6, n. 3, p. 453-459, 2002.
XAVIER, T.M.B.S. Tempo de Chuva: Estudos Climáticos e de Previsão Para o Ceará e Nordeste Setentrional. Fortaleza: ABC Editora, 2001.

SOUZA, E.B., ALVES, J.M.B.; REPELLI, C.A. A variabilidade espacial da precipitação sobre o estado do Ceará. In: Anais do 10 Congresso Brasileiro De Meteorologia, Campos do Jordão, pp. 196-200, 1996.

SUDENE - Superintendência do Desenvolvimento do Nordeste. Delimitação do Semiárido. 2017. Disponível em: http:// antigo.sudene.gov.br/delimitacao-do-semiarido, acesso em 26 fev. 2021

License information: This is an open-access article distributed under the terms of the Creative Commons Attribution License (type CC-BY), which permits unrestricted use, distribution and reproduction in any medium, provided the original article is properly cited. 